\title{
A randomized controlled trial comparing results of closed reduction and plaster immobilization versus external fixator in unstable fractures of distal radius
}

\author{
H.K. Gupta ${ }^{1}$, M.P. Singh ${ }^{2}$ \\ ${ }^{1}$ Lecturer, Dept. of Orthopaedics, College of Medical Sciences, Teaching Hospital, Bharatpur, Nepal \\ ${ }^{2}$ Professor, University College of Medical Sciences, Delhi University, New Delhi.
}

\begin{abstract}
s
To evaluate the functional and radiological outcome of the two different modalities in unstable fracture distal end of radius, and the complications in each group.

Study consists of prospective analysis of the cases of unstable fracture of distal end of radius managed by two different methods of treatment in 40 patients and the functional outcome measured by the standardized functional scoring method (Gartland and Werley 1951, Stewart et al. 1984). The radiological outcome of the fracture management as mentioned above measured according to Anatomical scoring method (Stewart et al. 1984).

In this study there was no statistical difference between functional and anatomical outcome when treated by either method. There was no poor graded result anatomically or functionally in either group. No serious complication was noted in both the groups.

Both the method of treatment produced no significant difference in outcome, functionally and anatomically , but the extra cost of anaesthetic drugs, operation theatre charges, hazards of anaesthesia and the cost of implants can be avoided in cases managed with closed reduction and immobilization in plaster cast.
\end{abstract}

Key words: Fracture distal radius, plaster cast in distal radius fracture, external fixation.

\section{Introduction}

The fractures of distal end of radius are common injuries and are the commonest bony injuries around the wrist. These fractures have often been considered primarily in elderly females but now it is increasingly more common in younger patients

Correspondence :H. K. Gupta

E-mail: hmntkg@yahoo.com who are exposed to severe trauma either in road traffic accident or playground etc.

Although the optimum treatment of fracture distal radius remains controversial, functionally good results can be expected in most patients treated by closed reduction and plaster cast immobilization. 
H.K. Gupta et al, A randomized controlled trial comparing results.

There are some fractures of distal radius, particularly when badly comminuted or intraarticular, present specific problems in management. ${ }^{1}$ The problems are related to instability of the fracture due to comminution of dorsal cortex and intra-articular extension. The intra-articular fractures of distal radius are usually result of high energy injury and often associated with poor outcome if the intra-articular congruity, radial length and fracture alignment not properly maintained. Various method have been described to avoid loss of reduction after closed reduction like plaster immobilization, external fixation, use of percutaneous pinning of distal radius, use of longitudinal pins and internal fixation etc. ${ }^{2-5} \mathrm{All}$ have claimed success in varying degrees. This study was undertaken to evaluate the outcome when such fractures are treated by closed reduction and plaster immobilization against treatment by external fixation.

\section{Materials and methods}

The study was conducted at B.P. Koirala institute of health Sciences, Dharan in between January 2006 to December 2007. The cases of fracture distal end of radius who satisfied the following criteria were included in study.

1. Age less than 50yrs,

2. Fracture distal radius with dorsal angulation more tha 20 degrees,

3. Severer dorsal comminution,

4. Radial shortening more than $10 \mathrm{~mm}$ and

5. Fracture involving wrist joint.
The exclusion criteria were severe osteoporosis, pathological fracture and multiple fracture involving same limb that could interfere with outcome of treatment of fracture distal end of radius. Fracture of distal radius were classified as per Frykmans classification ${ }^{6}$ as follows:

Type 1 Extra-articular fracture of distal radius, no fracture of ulna

Type 2 Extra-articular fracture of distal radius, fracture of ulnar styloid process

Type 3 Intra-articular, radiocarpal fracture of distal radius, no fracture of ulna

Type 4 Intra-articular, radiocarpal fracture of distal radius, fracture of ulnar styloid process

Type 5 Intra-articular, radioulnar fracture of distal radius, no fracture of ulna

Type 6 Intra-articular, radioulnar fracture of distal radius, fracture of ulnar styloid process

Type 7 Intra-articular, radiocarpal and radioulnar fracture of distal radius, no fracture of ulna

Type 8 Intra-articular, radiocarpal and radioulnar fracture of distal radius, fracture of ulnar styloid process

The total of fourty patients were enrolled in the study and they were randomly kept in two equal groups, namely, Group A and Group B. In Group A, all the patients were treated with closed reduction and long arm cast was applied under brachial plexus block. The reduction was confirmed by check radiograph on the same day (Fig $1 \&$ Fig 2 ). Then the patients were followed after one week 
for check radiograph for any displacement. The plaster was removed at six weeks and then physiotherapy of the affected limb was started. They all were reassessed at 3 months clinically and with radiograph of the wrist for functional and anatomical outcome. In Group B, all the patients were treated with closed reduction and external fixation. All of the cases were operated under brachial plexus block. They were given IV antibiotics preoperatively. An open technique was used to place two Schanz pin of size $3.5 \mathrm{~mm}$ in radius and two schanz pins of size $2.5 \mathrm{~mm}$ in $2^{\text {nd }}$ metacarpal. Due care was taken not to damage tendons and nerves during procedure. The distractor rod was placed on the radial side and polyaxial clamp were used ( Fig3 \& Fig4 ). All the patients were taught regarding pin-site care and physiotherapy for mobilization of fingers, elbow and shoulder. They were followed up fortnightly and implant removed at six weeks and they were encouraged further physiotherapy and called after 3 months for evaluation.

In both the groups, the patients were evaluated clinically and x-ray of affected wrist taken to evaluate the functional and anatomical outcome as per the scoring method the functional outcome measured by the standardized functional scoring method (Table 1). The radiological outcome of the fracture management as mentioned above measured according to Anatomical scoring method (Table 2).Any complications were noted. Total expenditure incurred during treatment were also noted .

Table 1 : Functional scoring method (Gartland and Werley 1951, Stewart et al. 1984) ${ }^{7}$

Subjective complaints

\begin{tabular}{|c|c|c|c|c|c|}
\hline Pain & $\begin{array}{l}\text { nitation of } \\
\text { ovement }\end{array}$ & Disability & $\begin{array}{l}\text { Restriction of } \\
\text { activity }\end{array}$ & $\begin{array}{l}\text { Result and } \\
\text { score }\end{array}$ & \\
\hline None & None & None & None & Excellent & 0 \\
\hline Occasional & Slight & None & None & Good & 2 \\
\hline Occasional & Slight & Minor & Some & Fair & 4 \\
\hline Often & Present & Definite & Marked & Poor & 6 \\
\hline \multicolumn{6}{|c|}{ Objective evaluation } \\
\hline \multicolumn{2}{|c|}{ Movement/function } & Range (degrees) & \multicolumn{3}{|c|}{ Score } \\
\hline \multicolumn{2}{|l|}{ Dorsiflexion } & $<45$ & \multicolumn{3}{|c|}{5} \\
\hline \multicolumn{2}{|c|}{ Palmar flexion } & $<30$ & \multicolumn{3}{|c|}{1} \\
\hline \multicolumn{2}{|c|}{ Ulnar deviation } & $<25$ & \multicolumn{3}{|c|}{3} \\
\hline \multicolumn{2}{|c|}{ Radial deviation } & $<15$ & \multicolumn{3}{|c|}{1} \\
\hline \multicolumn{2}{|l|}{ Supination } & $<50$ & \multicolumn{3}{|c|}{2} \\
\hline \multicolumn{2}{|l|}{ Pronation } & $<50$ & \multicolumn{3}{|c|}{2} \\
\hline \multicolumn{2}{|c|}{ Circumduction } & Loss & \multicolumn{3}{|c|}{1} \\
\hline \multicolumn{2}{|c|}{ Finger flexion } & Not to distal crease & \multicolumn{3}{|c|}{1 to 2} \\
\hline \multicolumn{2}{|l|}{ Grip } & Loss of strength & \multicolumn{3}{|c|}{1} \\
\hline \multicolumn{2}{|c|}{ Radial/median neuritis } & Mild-severe & \multicolumn{3}{|c|}{1 to 3} \\
\hline
\end{tabular}

Final grade: excellent, 0 to 2; good, 3 to 8 ; fair, 9 to 14; poor, $>15$ 
H.K. Gupta et al, A randomized controlled trial comparing results.

Table 2: Anatomical scoring method (Stewart et al. 1984) ${ }^{7}$

Final measurement

\begin{tabular}{cccc}
\hline $\begin{array}{c}\text { Dorsal angulation } \\
\text { (degrees) }\end{array}$ & $\begin{array}{c}\text { Loss of radial } \\
\text { length }(\mathrm{mm})\end{array}$ & $\begin{array}{c}\text { Loss of radial } \\
\text { angle(angle) }\end{array}$ & $\begin{array}{c}\text { Score for each } \\
\text { measurement }\end{array}$ \\
\hline Neutral & $0-3$ & $0-4$ & 0 \\
$1-10$ & $3-6$ & $5-9$ & 1 \\
$11-14$ & $7-11$ & $10-14$ & 2 \\
$>15$ & $>12$ & $>15$ & 4 \\
\hline
\end{tabular}

Final grade from addition of scores: excellent- 0 , good- 1 to 3 , fair- 4 to 6 and poor- 7 to 12

Statistical methods: The data was entered in Microsoft Excel 8 file. Success of this study was tested by comparing descriptive variables like age, sex, type of fracture between the two groups. Magnitude of difference was measured as difference between means in both groups and significance of difference was measured by determining $p$ value using Anova/Kruskal Wallis statistics depending upon whether the value of $p$ obtained from Bartlett's test for homogeneity of variance was below or above 0.05 , when the value of $\mathrm{P}$ was less than $0.05, \mathrm{KW}$ test was performed.

\section{Results}

Preoperative variables were comparable as shown in table 3. All fractures were managed by closed reduction and cast application in Group A and external fixator with polyaxial clamps in Group B. All the cases in Group A were treated with closed reduction and plaster immobilization, the mean age

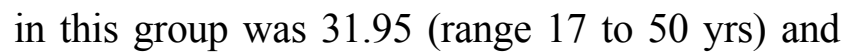
SD 11.50. They were followed up for $88.60 \pm 16.59$ days. In Group B , cases were treated with external fixator with poly axial clamp and distractor rod. The mean age was 38.68 years with SD 10.03 and the range was 16 to 50 yrs. The mean follow up was $91.47 \pm 4.86$ days. From this group, one case was excluded from the study due to non union of fracture and regarded as worst case.

Table 3: Pre operative variables in between group 1 and group 2.

\begin{tabular}{lcccc}
\hline Variables & $\begin{array}{l}\text { Group A } \\
(\mathrm{M} \pm \mathrm{SD})\end{array}$ & $\begin{array}{c}\text { Group B } \\
(\mathrm{M} \pm \mathrm{SD})\end{array}$ & $\begin{array}{c}\text { P } \\
\text { values }\end{array}$ \\
\hline Age (years) & $33.00 \pm 10.1837 .89 \pm 9.630 .1320$ \\
Sex & $\mathrm{M}$ & 14 & 17 & 0.559 \\
& $\mathrm{~F}$ & 6 & 3 & \\
Type of fracture & FC 3 & 6 & 8 & 0.466 \\
& FC 4 & 4 & 4 & \\
& FC 5 & 7 & 2 & \\
& FC 6 & 2 & 3 & \\
& FC 8 & 1 & 2 & \\
\hline
\end{tabular}

At final follow up, the clinical and radiological findings were as in table 4 and table 5. In this study 
Journal of College of Medical Sciences-Nepal, 2011, Vol-7, No-4

there was no statistical difference between the anatomical and functional outcome when treated by either method. No serious complication was noted in both the groups. There was one case in group A reported with tight plaster cast second day, the plaster was spitted on the $2^{\text {nd }}$ day follow up in OPD. The plaster was re applied on 4th day. There was pin tract infection in one case in Group B which healed with oral antibiotics. The total expenditure incurred was significantly less in Group A.

Table 4:Comparing outcome in both the groups

\begin{tabular}{lcccccc}
\hline & & Excellent & Good & Fair & Poor & P value \\
\hline Anatomical grading & Group A & 1 & 14 & 2 & 3 & 0.1872 \\
& Group B & 3 & 12 & 4 & 0 & \\
Functional grading & Group A & 0 & 17 & 1 & 2 & \\
& Group B & 3 & 16 & 0 & 0 & \\
\hline
\end{tabular}

Table 5.

\begin{tabular}{lccc}
\hline & Group $\mathrm{A}(\mathrm{M} \pm \mathrm{SD})$ & Group B(M $\pm \mathrm{SD})$ & P value \\
\hline Loss of radial length $(\mathrm{mm})$ & $6.00 \pm 7.53$ & $4.52 \pm 4.31$ & 0.630 \\
Loss of radial angle (degree) & $5.65 \pm 5.81$ & $2.89 \pm 2.97$ & 0.201 \\
Dorsal angulation & $6.65 \pm 7.05$ & $5.42 \pm 5.30$ & 0.543 \\
Expenditure incurred (Rs) & $1894.30 \pm 251.11$ & $8156.84 \pm 377.33$ & 0.00 \\
\hline
\end{tabular}

\section{Discussion}

Despite the fracture of distal radius being common the management is still controversial and various options for treatment have been described with varying degree of success.

Depalma et al. had proposed that the capsuloligamentous structures remain intact even in most severe fracture and facilitate reduction of fracture in sustained traction (ligamentotaxis), which formed the basis for external fixator ${ }^{2}$. The period of immobilization varies from four weeks to ten weeks, whereas Howard et al had shown in their study that at three months the functional outcome was comparable statistically but differed at six months follow up. He had recommended period of immobilization for six weeks. They concluded that external fixator produced significantly better anatomical and functional results but the use of the fixator in less comminuted fracture was unclear ${ }^{8}$. Bradely et al had laid emphasis on maintaining reduction of fracture by open reduction and internal fixation ${ }^{5}$. Harris et al. 
H.K. Gupta et al, A randomized controlled trial comparing results.

conclued in their study that the patients with distal radius fracture treated with external fixator were found to have superior result with respect to functional outcome in comparison to them treated with plaster immobilization. They observed that there was less loss of radial length, better grip and better functional outcome with external fixator when followed for an average of four years ${ }^{9}$. Jakim et al. showed that external fixator had good results in their study in functional and radiological outcome and also proposed combined approach along with percutaneous or limited open reduction. They also had showed in their results that external fixator was a better option to treat comminuted and unstable fractures for better functional and anatomical results. In their study the average final radial angulation was 20.5 degrees, normal 22 degrees and average final shortening was $1.8 \mathrm{~mm}$ (range 0 to $10 \mathrm{~mm}$ ). The final volar angulation averaged 2 degrees. Merchan EC et al showed in their study that external fixator produced better results. It has been suggested in literature that the external fixator is warranted in younger patients with strong bony cortices ${ }^{11}$. Cooney et al had stressed the importance of anatomic correction of the fracture of distal radius by various methods of external fixation to achieve it. Improved anatomic results (Cooney et al.1979; D Anca et al. 1984; Jenkins et al.1987) have been proven with external fixators ${ }^{12-14}$.Howard et al. also made study upon external fixator versus plaster cast immobilization and came to similar conclusion. Broos et al found external fixators to have more superior results then plates and screws and found no difference between static and dynamic fixators. ${ }^{15}$ Horne JG et al. had done prospective randomized trial of external fixation and plaster cast immobilization in treatment of fracture distal end of radius, found no advantage of using an external fixator to maintain reduced distal radial fracture in patients less than 60 years. The external fixator group had significant complication rate too in their study ${ }^{16}$ Horne JG et al had similar study and showed that there was advantage in using external fixator over the plaster .In addition the external fixator group had risk of significant complication rate. The result of our study also goes along with their conclusion ${ }^{16}$. Vaughan et al had used Roger Anderson type external fixators and had concluded the external fixators having good results in unstable distal radius fracture ${ }^{17}$. In this study there was no statistical difference between the anatomical and functional outcome when treated by either method. However there was no poor graded result anatomically in fixators group and more of excellent results as per the scoring system. No serious complication was noted in both the groups. The functional outcome in both the groups did not differ statistically but the there were no poor or fair graded results seen in group B as seen in Group A. In this study the loss of radial length was $4.52 \pm 4.31 \mathrm{~mm}$ in group B whereas $6.00 \pm 7.53 \mathrm{~mm}$ in Group A indicating better maintenance of radial length in case of external fixation. There was loss of radial angulation of $2.89 \pm 2.97$ degrees in group B where as 5.65 \pm 5.81 degrees in Group A. The final loss of dorsal angulation was $6.65 \pm 7.05$ degrees in POP cast group and 5.42 \pm 5.30 degrees in fixator group. The follow up was for around 3 months only and the functional outcome was not significantly different in both the groups at last follow up. The average loss of radial length, radial angulation and 
dorsal angulation was less in Group B, treated with external fixator.

The total expenditure incurred was significantly less in POP cast Group, when compared to total expenditure incurred in fixator group $(\mathrm{p}=0.00)$. The cause for excessive expenditure in Group B was due to cost of anesthetic drugs, implants and operation charges. The cases in Group A received treatment earlier than those in Group B, and there was significant difference of the time interval between injury and management in both groups $(\mathrm{p}$ value 0.0154 ). The reason for this was attributed to the time taken to prepare the patients for taking operation theatre, getting appropriate routine investigations for pre-anesthetic clearance, arranging implants and drugs.

In conclusion, both the methods of treatment produced no significant difference in outcome, functionally and anatomically, but the extra cost of anesthetic drugs, operation theatre charge, hazards of anesthesia, cost of implant can be avoided in cases of closed reduction and immobilization in plaster cases.

\section{References}

1. L. Solomon, J.W. Devid, N. Selvadrai. Injuries of the forearm and Wrist. In; apley's system of Orthopaedics and fracture. $8^{\text {th }}$ Edi. London, Arnold Publishers. 2001:620.

2. A.F. DePalma. Comminuted fractures of the distal end of the radius treated by ulnar pinning. $J$ Bone Joint Surg [Am] 1952;34-A:651-62.

3. R. Anderson, G. O'Neil. Comminuted fractures of the distal end of the radius. Surg Gynecol Obstet 1944; 78:434-40.
4. L.V. Rush, H.L. Rush. Longitudinal pin fixation on Colles' fracture of the wrist. South Surg 1949;15:679-86.

5. J.K. Bradway, P.C. Amadio, W.P. Cooney. Open reduction and internal fixation of displaced, comminuted intra-articular fractures of the distal end of the radius. J Bone Joint Surg [Am] 1989; 71-A: 839-47.

6. G. Frykman. Fracture of the distal radius including sequalae - shoulder-hand-finger syndrome, disturbance in the distal radio-ulnar joint and impairment of nerve function: a clinical and experimental study. Acta Orthop Scand 1967:Suppl 108.

7. H.D. Stewart, A.R. Innes, F.D. Burke. Factors affecting the outcome of Colles' fractures: an anatomical and functional study. Injury 1985;16(5):289-95.

8. P.W. Howard, H.D. Stewart, R.E. Hind, Burke. External fixation or plaster for severely displaced comminuted colles' fractures? a prospective study of anatomical and functional results . J Bone Joint Surg (Br) 1989 : 71-b: 68-73.

9. H. Kapoor, A. Agarwal, B.K. Dhaon. Displaced intraarticular fractures of distal radius: comparative evaluation of results following closed reduction, external fixation and open reduction with internal fixation. Injury. Int. J. Care Injured 2000;31:75-6.

10. I. Jakim, H.S. Pieterse, M.B.. Sweet. External fixation for intra-articular fractures of the distal radius. J Bone Joint Surg (Br) 1991:73-B:302-6.

11. W.A. Grana, J.A. Kopta. The Roger Anderson device in the treatment of fractures of the distal end of the radius. J Bone Joint Surg [Am]1979;61-A:1234-8.

12. W.P. Conney WP, R.L. Linscheid, J.H. Dobyns. External pin fixation for unstable Colles' fractures. $J$ Bone Joint Surg [Am] 1979;61-A:840-5.

13. A.F. D'Anca, S.B. Sternlieb, T.W. Byron, et al. External fixators management of unstable Colles' fractures: an alternative method. Orthopaedics 1984;7:853-9. 
H.K. Gupta et al, A randomized controlled trial comparing results.

14. N.H. Jenkins, D.G. Jones, S.R. Johnson, et al. External fixation of Colles' fractures: an anatomical study. $J$ Bone Joint Surg [Br] 1987;69-B:207-11.

15. P.L. Broos, I.A. Foourneau, D.V. Stoffelen. Fractures of distal radius. Current concept and review. Aacta Orthopaedica Belgica 2001;.67(3):211-8.
16. J.G. Horne, P. Devane, G. Purdie. A prospective randomized trial of external fixator and plaster cast immobilisationin the treatment of distal radial fractures. J Orth Trauma 1990;4(1):30-4.

17. P.A. Vaughan, S.M. Lui, I.J. Harrington, et al. Treatment of unstable fractures of the distal radius by external fixation. J Bone Joint Sur [Br] 1985;67B:385-9. 